Review Article

\title{
Cutaneous manifestations in COVID-19
}

\author{
Luh P. V. C. Sari* \\ Department of Medical Bachelor and Medical Profession, Universitas Udayana, Denpasar, Bali, Indonesia
}

Received: 08 February 2022

Accepted: 22 February 2022

*Correspondence:

Dr. Luh PVC Sari,

E-mail: drvennycempaka@gmail.com

Copyright: (c) the author(s), publisher and licensee Medip Academy. This is an open-access article distributed under the terms of the Creative Commons Attribution Non-Commercial License, which permits unrestricted non-commercial use, distribution, and reproduction in any medium, provided the original work is properly cited.

\begin{abstract}
Despite of primarily infecting the respiratory tract, coronavirus disease 2019 (COVID-19) may have an extensive extrapulmonary clinical manifestations, including the integumen system. Cutaneous manifestations of COVID-19 are polymorphic, hence it can be confused with any other identical lesions caused by other agents. This literature review concludes the cutaneous manifestations which can be found in COVID-19. COVID-19 may manifest as maculopapular rash, urticaria, vesicular lesions, covid toes, and livedo recamosa. Some of these cutaneous manifestations may have a significant prognostic value for diagnosing COVID-19. Although COVID-19 role in the integumen system is poorly understood, proper identification are needed to distinguish these lesions from different etiological agents.
\end{abstract}

Keywords: COVID-19, Extrapulmonary, Cutaneous, Skin

\section{INTRODUCTION}

The first case of acute respiratory distress syndrome (ARDS) was reported in Wuhan, Hubei, China, in December 2019. The disease was tentatively named as Novel Coronavirus (2019-nCoV). On February 11, 2020, the World Health Organization (WHO) officially announced the name of the emerging disease associated with the new coronavirus as Coronavirus Disease 2019 (COVID-19). Corona virus (COVID-19) is a large family of viruses that cause respiratory tract infections, ranging from the common cold to serious illnesses. Since then, the disease caused by this virus, called "coronavirus disease-19" (COVID-19), has spread around the world with staggering speed into a pandemic emergency. WHO declared Covid-19 a pandemic on March 12, 2020. As of August 29, 2020, there were 169,195 positive cases in Indonesia, 7,261 deaths and 122,802 recoveries. Globally, there are 24,537,560 confirmed cases of Covid19 , including 832,879 deaths. ${ }^{1}$ The most common clinical manifestations of COVID-19 are fever and respiratory symptoms, but recently several different extrapulmonary manifestations have been reported, including dermatological signs. While skin manifestations associated with COVID-19 are increasingly being reported, their pathophysiological mechanisms are largely unknown, and the direct or indirect role of SARS-CoV-2 in its pathogenesis is still debated. In addition, evidence is accumulating that the skin manifestations associated with COVID-19 are highly polymorphic. ${ }^{2}$

The most common skin manifestation is a maculopapular rash. The skin manifestations of COVID-19 are important in establishing the diagnosis and can be prognostic value for the disease. Some skin manifestations that occur in COVID-19 patients include acral areas of erythema with vesicles or pustules (pseudo-chilblains), other vesicular eruptions, urticarial lesions, maculopapular eruptions and livedo or necrosis. The appearance of skin manifestations in patients with COVID-19 cannot be predicted, vesicular eruptions are found to appear early in the course of the disease, whereas chilblain-like lesions often appear late during the course of the disease, and can continue to develop also have a longer duration of eruption than other skin manifestations. ${ }^{2}$ 


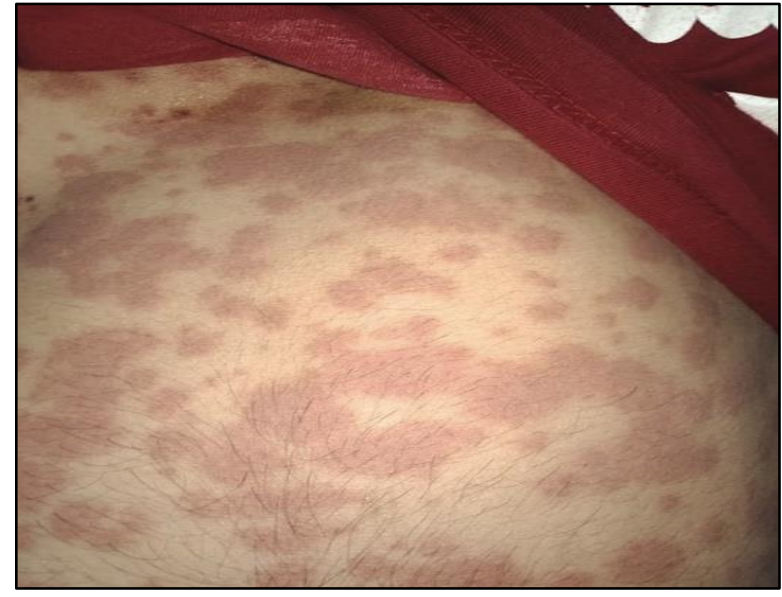

Figure 1: Multiple discrete and confluent erythematous, edematous papules, and plaques on the trunk. ${ }^{9}$



Figure 2: Urticarial erythematous eruption affecting the face, neck and upper chest. ${ }^{14}$

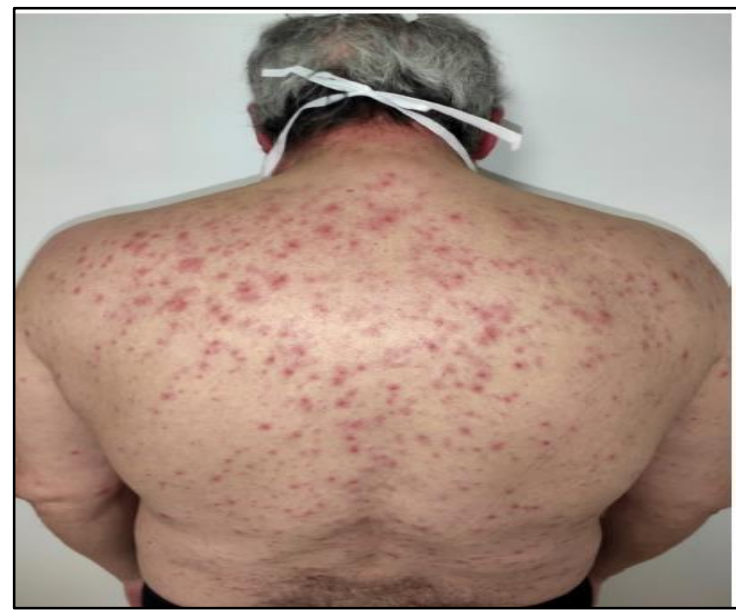

Figure 3: Vesicular rash in COVID-19 patients. Papules and vesicles of varying sizes affecting thewhole trunk. ${ }^{17}$

The skin manifestations that appear in patients with COVID-19 look similar to skin lesions caused by other viruses. ${ }^{2,3}$ Therefore, this literature review was conducted to discuss the skin manifestations of COVID-19, in order to better understand the skin manifestations in COVID-19 patients.

\section{EPIDEMIOLOGY}

The first case of COVID-19 was discovered in December 2019 in Wuhan, China. After that, the SARS-Cov-2 virus spread to all parts of China within a few weeks, and to other countries within a few months. As of July 2021, COVID-19 has been found in 216 countries, with a total of more than 190,000,000 confirmed cases. ${ }^{4,5}$ The first confirmed case of COVID-19 in Indonesia was reported 2 patients on March 2, 2020. Until July 2021, COVID -19 in Indonesia has approached 3,000,000 confirmed cases and is ranked 14th in the total cumulative COVID-19 cases in the world. ${ }^{6}$

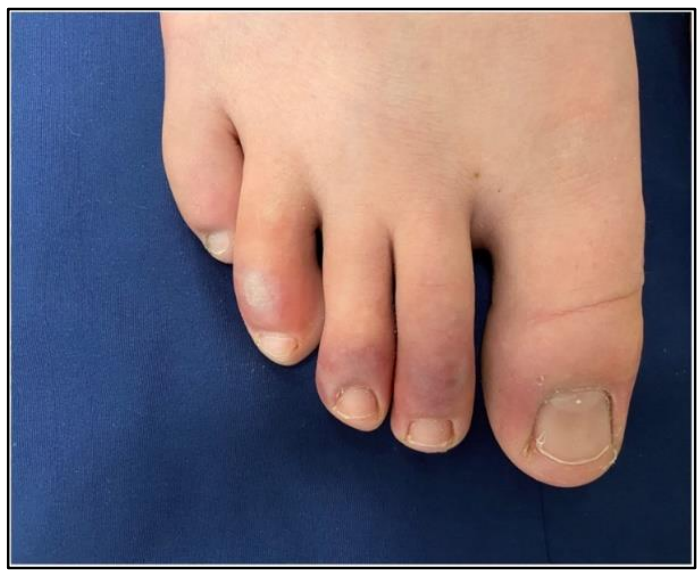

Figure 4: Clinical features of covid toes in a healthy adolescent, with purplish erythematous macules located on the toes. ${ }^{18}$

Cases in several countries show manifestations of COVID-19 on the skin. Recalcati et al described $20.45 \%$ of COVID-19 patients treated at Lecco Hospital (Lombardy region, Italy) as manifesting an erythematous rash $(n=14)$, widespread urticaria $(n=3)$ or varicella-like vesicles $(n=1)$. Eight of these patients experienced skin symptoms at the time of initial infection, while 10 patients after hospitalization. ${ }^{7}$ This is in line with the study by Giavedoni, et al. in Barcelona who reported that $58(2.1 \%)$ of 2,761 patients who were confirmed positive for COVID-19 complained of skin manifestations. ${ }^{8}$ Until now, data on the incidence of skin manifestations in COVID-19 patients in Indonesia is still scarce. However, several case reports from various hospitals have described the presence of various skin lesions.

\section{COVID-19 MANIFESTATIONS ON THE SKIN}

\section{Maculopapular rash}

A maculopapular rash, which is mostly spread over the trunk, is reported to be the most common skin manifestation in COVID-19 patients. Rash was 
associated with itching in $56 \%$ of patients and was observed together with COVID-19 symptoms. ${ }^{9}$ In the review by Sachdeva and Gianotti, skin lesions were the presenting feature in $12.5 \%(9 / 72)$ of patients and maculopapular rash was seen in $36.1 \%(26 / 72)$ patients. ${ }^{10}$ A prospective study by Casas et al. found five major clinical patterns of rash including maculopapular rash (47\%), urticaria (19\%), pseudo-chilblains (19\%), vesicles $(9 \%)$, and livedo or necrosis $(6 \%){ }^{3}$

The maculopapular rash results from the presence of diffuse microvascular vasculitis due to complement activation. Another theory mentions the finding of a high number of lymphocytes without eosinophils, edema of the stratum papillary dermis, spongiosis of the epidermis, and lymphohistiocytic infiltrates. No correlation was observed between the presence of skin lesions and the severity of the disease. In addition to the maculopapular rash, in some cases the rash that appears resembles the lesions of erythema multiforme. ${ }^{11}$

There are several other diseases that also have maculopapular lesions, including viral exanthema, scarlet fever, rubella, drug eruptions, and secondary syphilis. The number of differential diagnoses for maculopapular rash is a challenge for medical personnel to determine the right diagnosis. Therefore, during the COVID-19 pandemic, it is important to be able to distinguish the etiology of skin rashes to avoid misdiagnosis. ${ }^{9}$ An example of maculopapular rash in COVID-19 patient can be seen in (Figure 1).

\section{Urticaria}

Urticaria tends to occur in elderly COVID-19 patients, where women have a higher risk than men. According to research by Rahimi and Tehranchinia, there were 19 patients who had uticaria. The mean age of the patients was 47.6 years. Uticaria is characterized by local edema that appears quickly and disappears over a long period of time. On the surface of the skin, the lesions are reddish and pale, elevated, and surrounded by a halo. Urticaria can appear on the head, trunk, extremities, and palms and soles. On biopsy found perivascular lymphocytic infiltrate, eosinophils, edema in the upper dermis layer. The condition of uticaria is often seen with angioedema. ${ }^{12}$

A case report in India by Mariyath et al found that urticaria was the second most common skin lesion $(16.7 \%)$ occurring in patients with COVID-19 after maculopapular rash. ${ }^{9}$ Henry et al also reported that there were COVID-19 patients in France with urticaria, complained of itching in the facial and acral areas accompanied by joint pain, then 48 hours later a fever appeared followed by respiratory symptoms. ${ }^{13}$ Therefore, the appearance of urticaria can be used as a prodromal sign of COVID-19 infection so that health workers can carry out testing, tracking and tracing earlier. ${ }^{14}$ Urticaria can be a clinical manifestation of various other diseases such as allergic reactions, anaphylactic reactions, angioedema, to autoimmune diseases such as lupus erythematosus. Urticaria accompanied by fever needs to be considered because it can be a sign of COVID-19 infection. An example of urticarial erythema can be seen in Figure 2.

\section{Vesicular lesions}

According to Rahimi and Tehranchinia's research conducted on 450 patients, there were various types of skin manifestations of COVID-19 patients, $15 \%$ of the total sample showed skin manifestations that appeared in the form of vesicular lesions $(15.5 \%)$. conducted by Sachdeva, et al. found skin manifestations in $34.7 \%$ of cases of COVID-19 were vesicular lesions. ${ }^{10}$ Vesicular lesions that appear are usually small in size with a monomorphous form and appear most often on the trunk, upper and lower extremities until they can spread to the entire body surface. Vesicular lesions appear first, then after 3 days symptoms of fever appear followed by respiratory symptoms of cough and shortness of breath. It occurs more frequently in middle-aged people with moderate to severe disease severity. ${ }^{3,15}$

However, the things mentioned above contradict the results of a study conducted by Fernandez-Nieto et al which stated that vesicular rashes were divided into two morphological types, diffuse patterns and localized patterns. A diffuse pattern was found in 18 patients (75\%), consisting of small papules, vesicles and pustules of various sizes, up to $7-8 \mathrm{~mm}$ in diameter. The lesions appear at the same time and then cluster at several points. The spread of the lesions tends to be on the trunk and exyremitas. A local pattern was found in 6/24 patients (25\%) consisting of monomorphic lesions, up to $3-4 \mathrm{~mm}$ in diameter, appearing simultaneously on one area of the patient's body. Usually involved is the center of the chest / upper abdomen or back. ${ }^{16}$ In vesicular lesions, histologically, it was observed that there was no inflammatory infiltrate. The epidermis appeared atrophic, hyperkeratosis with a basket weave pattern, stratum basale vacuolization, multinucleated keratinocytes, and dyskeratotic cells. ${ }^{17}$

Other viral diseases can also cause vesicular lesions, for example in varicella, herpes zoster, herpes simplex, and pemphigoid. Other onset and predilection of skin lesions and accompanying symptoms can be clues to the etiology of these vesicular lesions. ${ }^{16,17}$ An example of vesicular rash in COVID-19 patient can be seen in Figure 3.

\section{COVID toes}

Covid toes usually appear late in the course of the disease and are not a marker of the severity of COVID-19 disease. Covid Toes usually appear in young patients, especially in children, adolescents, and young adults who are stated to be in good health and have no specific medical history. ${ }^{18}$ Skin manifestations initially appear in the form of erythematous papules and edema followed by 
minimal itching and pain. Vesicles and pustules may also be found with areas of purpura. These lesions are similar to lesions that appear in response to cold temperatures, namely chilblains, so that covid toes are often called "pseudo-chilblains". ${ }^{19}$ Histopathology shows endothelial swelling to necrosis and fibrinoid thrombosis. Purpura, superficial and deep perivascular lymphocytic inflammation with peri-eccrine accentuation, edema, and mild vacuolar interface damage are also seen. In addition, during examination using an electron microscope, corona virus particles were also found. ${ }^{18,19}$

Cappel, et al. reported $7 \%$ cases of chilblains-like eruptions with lesions on feet's skin, having positive results for the SARS-CoV-2 polymerase chain reaction (PCR). This is also directly proportional to the research conducted by Casas, et al. who reported $19 \%$ of COVID19 cases with covid toes.3,20 Skin manifestations resembling that of covid toes have also been seen in perniosis, vasculitis, Raynaud's phenomenon, lupus erythematosus, Buerger's disease, systemic sclerosis, and acrocyanosis. An example of covid toes can be seen in Figure 4.

\section{Livedo recamosa}

Livedo racemosa is a reddish or purplish skin rash with a web-like pattern. This skin rash is caused by narrowed blood vessels near the skin. Casas, et al. reported that Livedo racemose appeared in 21 cases $(6 \%)$ and tended to occur in elderly patients. Three of them, accompanied by itching. The burning sensation was also felt by two other patients, and one patient complained of a burning sensation in the skin lesions. ${ }^{3}$ This is also supported by the case report made by Khalil, et al. mentioned the appearance of livedo skin manifestations as a sign of presentation of severe acute respiratory syndrome coronavirus infection. Livedo racemosa is mostly found in the elderly group with severe COVID-19 severity with a mortality rate of $10 \%$. These lesions usually appear on the trunk, thighs, and legs. Necrotic tissue has also been reported in some cases. ${ }^{21}$ An example of livedo recamosa in COVID-19 patient can be seen in Figure 5.

\section{CONCLUSION}

COVID-19 is a respiratory infection caused by the SARS-CoV-2 virus. This virus can cause damage to various organs. Skin manifestations are rarely found, but several studies have shown that skin manifestations in COVID-19 patients are asymptomatic or in conjunction with other symptoms. Skin manifestations found in COVID-19 patients in several cases include morbiliform rash, urticaria, rash with petechiae, rash with purpura, papulovesicular lesions, chilblains and liveoid lesions. It is important to recognize these skin manifestations for early diagnosis of COVID-19, preventing transmission, providing appropriate treatment, and preventing complications that may occur.

\section{ACKNOWLEDGEMENTS}

The author is thankful to everyone for the support and for making this literature review possible to publish.

\section{Funding: No funding sources \\ Conflict of interest: None declared \\ Ethical approval: Not required}

\section{REFERENCES}

1. Organization WH. Global surveillance for COVID19 disease caused by human infection with the 2019 novel coronavirus, Interim guidance. 2020.

2. Marzano AV, Cassano N, Genovese G, Moltrasio C, Vena GA. Cutaneous manifestations in patients with COVID-19: a preliminary review of an emerging issue. Br J Dermatol. 2020;183:431-42.

3. Galván Casas C, Catala A, Carretero Hernández G, Rodríguez-Jiménez $\mathrm{P}, \quad$ Fernández-Nieto $\mathrm{D}$, Rodríguez-Villa Lario A et al. Classification of the cutaneous manifestations of COVID-19: a rapid prospective nationwide consensus study in Spain with 375 cases. Br J Dermatol. 2020;183:71-77.

4. Organization WH. Weekly operational update on COVID-19. World Heal Organ Geneva, Switz. 2021;1-10.

5. Organization WH. Coronavirus disease (COVID19): situation report. 2020;162.

6. Kementerian Kesehatan Republik Indonesia. Situasi COVID-19.2021.

7. Recalcati S. Cutaneous manifestations in COVID19: a first perspective. J Eur Acad Dermatol Venereol. 2020;4:12-8.

8. Giavedoni $\mathrm{P}$, Podlipnik $\mathrm{S}$, Pericàs JM, Fuertes de Vega I, García-Herrera A, Alós L et al. Skin manifestations in COVID-19: prevalence and relationship with disease severity. J Clin Med. 2020;9:3261.

9. Mariyath OKR, Samad KA, Devi K, Surya VS, Effeena MD, Ajina M. Atypical maculopapular rash as the initial sign of COVID-19: A case report from a COVID hospital. J Ski Sex Transm Dis. 2021;3:87-90.

10. Sachdeva M, Gianotti R, Shah M, Bradanini L, Tosi D, Veraldi S, Ziv M et al. Cutaneous manifestations of COVID-19: Report of three cases and a review of literature. J Dermatol Sci. 2020;98:75-81.

11. Gottlieb M, Long B. Dermatologic manifestations and complications of COVID-19. Am J Emerg Med. 2020;38:1715-21.

12. Rahimi H, Tehranchinia Z. A comprehensive review of cutaneous manifestations associated with COVID-19. Biomed Res Int. 2020;2020.

13. Henry D, Ackerman M, Sancelme E, Finon A, Esteve E. Urticarial eruption in COVID-19 infection. J Eur Acad Dermatology Venereol. 2020.

14. Hassan K. Urticaria and angioedema as a prodromal cutaneous manifestation of SARS-CoV-2 (COVID- 
19) infection. BMJ Case Reports CP. 2020;13:e236981.

15. De Giorgi V, Recalcati S, Jia Z, Chong W, Ding R, Deng $\mathrm{Y}$ et 1 . Cutaneous manifestations related to coronavirus disease 2019 (COVID-19): A prospective study from China and Italy. J Am Acad Dermatol. 2020;83:674-5.

16. Fernandez-Nieto D, Ortega-Quijano D, JimenezCauhe J, Burgos-Blasco P, de Perosanz-Lobo D, Suarez-Valle A et al. Clinical and histological characterization of vesicular COVID-19 rashes: a prospective study in a tertiary care hospital. Clin Exp Dermatol. 2020;45:872-875.

17. Wang CJ, Worswick S. Cutaneous manifestations of COVID-19. Dermatol Online J. 2021;27.

18. Baeck M, Herman A. COVID toes: where do we stand with the current evidence? Int J Infect Dis. 2021; 102:53-5.

19. Colmenero I, Santonja C, Alonso-Riaño M, Noguera-Morel L, Hernández-Martín A, Andina D et al. SARS-CoV-2 endothelial infection causes COVID-19 chilblains: histopathological, immunohistochemical and ultrastructural study of seven paediatric cases. $\mathrm{Br} \mathrm{J}$ Dermatol. 2020;183:729-37.

20. Cappel MA, Cappel JA, Wetter DA. Pernio (chilblains), SARS-CoV-2, and COVID toes unified through cutaneous and systemic mechanisms. In: Mayo Clinic Proceedings. Elsevier. 2021;96:9891005.

21. Khalil S, Hinds BR, Manalo IF, Vargas IM, Mallela $\mathrm{S}$, Jacobs R. Livedo reticularis as a presenting sign of severe acute respiratory syndrome coronavirus 2 infection. JAAD Case Reports. 2020;6:871-4.

Cite this article as: Sari LPVC. Cutaneous manifestations in COVID-19. Int J Res Med Sci 2022;10:772-6. 